\title{
Isolation and characterization of nitrogen-fixing bacteria from soil sample in Dhaka, Bangladesh
}

\author{
Farzana Yasmin Shomi, Md. Borhan Uddin and Tamanna Zerin*
}

\author{
Department of Microbiology, Stamford University Bangladesh, 51, Siddeswari Road, Dhaka-1217, Bangladesh
}

Received 30 July 2021/Accepted 02 September 2021

\begin{abstract}
Biological nitrogen $\left(\mathrm{N}_{2}\right)$ fixation is very essential for limiting the growth of plants and agricultural crops. The present study was conducted to potentially isolate $\mathbf{N}_{2}$-fixing bacteria from garden soil sample at Stamford University Bangladesh, Siddeswari, Dhaka. Here, we used culture-dependent method to perform this experiment. Firstly, we collected garden soil sample, diluted and inoculated in $\mathrm{N}_{2}$-free Jensen's media by maintaining the aseptic procedure. We obtained 5 different colonies from soil samples. We cultured the isolates in $\mathbf{N}_{2}$-free Jensen's media containing bromothymol blue (BMB) and also, in Yeast Extract Mannitol Agar (YEMA) media containing congo red to confirm nitrogen fixation capacity. We collected the colony characteristics of all the isolates. Only 1A isolate showed good growth after $24 \mathrm{~h}$ of incubation among all the isolates. We performed ammonification test with Nessler reagent to confirm $\mathrm{N}_{2}$-fixing ability for our selected isolates. The $1 \mathrm{~A}$ isolate was positive in ammonification test. Culture, microscopy and biochemical tests were performed to identify isolate $1 \mathrm{~A}$. This isolate was presumptively identified as Azotobacter sp. In the present study, Azotobacter sp. that was isolated from the soil sample was found to be a potential $\mathbf{N}_{2}$-fixing bacterium. Isolate $1 \mathrm{~A}$ can be used for $\mathbf{N}_{2}$-fixation to boost production of crops.
\end{abstract}

Keywords: Azotobacter sp., $\mathrm{N}_{2}$-fixation, $\mathrm{N}_{2}$-free media, $\mathrm{N}_{2}$-fixing bacteria, biofertilizer.

\section{INTRODUCTION}

Nitrogen is an essential element for the growth and development of plants and agriculture. Nitrogen is the most abundant element in the atmosphere but it is biochemically unavailable for plants and most microbes as they depend upon combined or fixed forms of nitrogen (1). There are four sources from where plants can obtain these forms of "combined" nitrogen as the addition of ammonia and/or nitrate fertilizer or manure to the soil, the release of these compounds during organic matter decomposition, the conversion of atmospheric nitrogen into the compounds by natural processes, such as lightning, and biological nitrogen fixation (2). So, nitrogen fixation is an important process by which the molecular nitrogen in the air is turned into ammonia, nitrite or related nitrogenous compounds in soil (2). Biological nitrogen fixation (BNF) is performed by a special group of prokaryotes including bacterial and archaeal domains and they fix about $50 \%$ of the total nitrogen per year (1). These prokaryotes include aquatic cyanobacteria, free-living soil bacteria as Azotobacter, bacteria like Azospirillum which form an associative relationship with plants, and bacteria that form symbioses with legumes and other plants as Rhizobium and Bradyrhizobium (3, 4). The remaining $50 \%$ is fixed industrially as nitrogen fertilizer by the Haber Bosch process which provides most of the necessary amount of nitrogen to cropping systems. The Haber Bosch process brought a revolution in agricultural production as it met up the immediate demands for nitrogen as a fertilizer early in the twentieth century (2). Nitrogenous fertilizer production is not only expensive but also has harmful consequences to the environment. The harmful consequences include nitrogen oxides emission, eutrophication of water, acidification of soil, and worldwide environmental problems such as the formation of coastal dead zones (1). So, BNF is both economically and ecologically beneficial to sustainable agricultural production (1). The dependence on chemical fertilizers in agriculture must be reduced and there is significant research interest on biological nitrogen fixation and prospects for increasing its application in agricultural settings. However, the process is solely confined to bacteria and archaea and it does not occur in nitrogenous eukaryotes. Symbiotic nitrogen fixation is part of a mutualistic relationship where plants and bacteria are equally benefitted by sharing a niche and fixed carbon to bacteria in exchange for fixed nitrogen and it is restricted mainly to legumes in agricultural systems but there are a number of microorganisms, including some diazotrophs that inhabit the rhizosphere of other crop plants, some of which have been shown to enhance plant growth (5). It is well documented that BNF mediated by nitrogenase enzymes is a process important to the biological activity of soil. Nitrogenfixing free-living microorganisms have frequently been reported as plant growth promoters (6). Therefore, this study was conducted to isolate nitrogen-fixing bacteria from rhizospheric garden soil. Isolates were also characterized to determine their nitrogen-fixing ability time-dependently.

\section{MATERIALS AND METHODS}

Sample collection and processing. The sample was collected from the garden of Stamford University Bangladesh, Siddeswari, Dhaka on March, 2020. For soil collection, a sterile beaker, a marking pen, and a spatula were 
used. Sufficient amount of soil sample was collected from one point in the garden in a sterile beaker and tagged it. The sample was collected from the top $6 \mathrm{~cm}$ of the soil profile. This layer is the preferred zone of most of the microbial activities, where most of the bacterial population is concentrated.

Processing of soil sample. $1.0 \mathrm{~g}$ of soil sample was transferred in a sterile beaker containing $99 \mathrm{ml}$ of autoclaved normal saline and homogenized. One $\mathrm{ml}$ of homogenized soil sample was transferred into $9 \mathrm{ml}$ sterile normal saline and serial dilution was carried out from $10^{-1}$ to $10^{-8}$ dilutions.

Screening of nitrogen-fixing bacteria from soil. Serially diluted bacterial cultures $(100 \mu 1)$ were inoculated on Jensen's media, a nitrogen-free media and incubated at $37^{\circ} \mathrm{C}$ until growth was observed. Their colony morphology was noted and pure colonies were obtained by repeating subculture through streaking on Jensen's medium. Isolated colonies were streaked on Jensen's media containing Bromothymol Blue (BMB) and Yeast Extract Mannito Agar (YEMA) media containing Congo red to determine nitrogen fixation capacity. The Petri plates were kept in the incubator at $37^{\circ} \mathrm{C}$ until the growth was observed. Followed by incubation, the colony characteristics were noted.

Determination of nitrogen-fixation capacity of isolated bacteria using Nessler's reagent . The isolates were grown in peptone water, shaken at 100 $\mathrm{rpm}$, at $30^{\circ} \mathrm{C}$ for $3,5,7$ and 9 days. Following incubation, the broth wa centrifuged at 4,000 rpm for 20 minutes and the supernatant was reserved. After treatment with $0.5 \mathrm{ml}$ of Nessler's reagent to $1 \mathrm{ml}$ of supernatant, the sample develops color from yellowish to brown if ammonia is present there. The color intensity of the solution was found to correspond to the amount of ammonia present in the sample (7).

Morphological and biochemical characterization of nitrogen-fixing bacteria. The isolate that showed nitrogen-fixing capacity using Nessler's reagent was subjected to morphological identification through gram staining and biochemical characterization include oxidase, catalase, triple sugar iron (TSI), motility indole urea (MIU), citrate, methyl red (MR), voges-proskauer (VP), and starch hydrolysis tests (8).

\section{RESULTS}

Isolation and characterization of nitrogen-fixing bacteria. Five different microbial colonies were found on Jensen's media from soil samples. The isolates were marked as A1, A2, A3, A4 and A5. We in Table 1. Isolate A1 was taken to continue for further work for its rapid growth and cultural characteristics as a potential nitrogen fixer. The growth on Jensen's BMB media of isolate A1 is shown in Figure 1.

Determination of nitrogen-fixing capacity of the selected isolate. Ammonification test was performed using Nessler reagent to determine $\mathrm{N}_{2}$ fixing ability of A1 isolate. Time-dependent ammonia production potential was qualitatively measured from 0 to $9^{\text {th }}$ day of incubation and showed in Table 2. With the time of incubation, the production of ammonia was increased till the $9^{\text {th }}$ day.

The microscopic morphology and biochemical properties of isolate A1 from soil sample is presented in Tables 3 and 4, respectively. The isolate was presumably identified as Azotobacter sp.

\section{DISCUSSION}

Bangladesh is a developing country with a huge population that depends much on agriculture. So, crop development is essential for Bangladesh to meet up the huge demand of the population. Chemical fertilizers have good results on crop production but at the same time, it is not so cheap and it is polluting the whole environment causing harm to plants, animals, and humans. So, $\mathrm{N}_{2}$-fixing microorganisms can be a

Table 1. Colony characteristics of isolated bacteria from garden soil.

\begin{tabular}{|c|c|c|c|c|c|c|}
\hline Media & Morphology & A1 & A2 & A3 & A4 & A5 \\
\hline \multirow{5}{*}{ NA } & color & watery & yellow, light zone & white & white & yellow \\
\hline & size & large & very large & large & small & pinpoint \\
\hline & form & convex & circular & wrinkled & undulate & convex \\
\hline & elevation & raised & raised & flat & raised & raised \\
\hline & Media color & unchanged & unchanged & unchanged & unchanged & unchanged \\
\hline \multirow{5}{*}{$\begin{array}{l}\text { JENSEN+ } \\
\text { BMB }\end{array}$} & color & watery & yellow & white & white & yellow \\
\hline & size & small & very large & large & small & pinpoint \\
\hline & form & convex & circular & wrinkled & undulate & convex \\
\hline & elevation & raised & raised & flat & raised & raised \\
\hline & Media color & yellow & unchanged & unchanged & unchanged & unchanged \\
\hline \multirow{5}{*}{$\begin{array}{l}\text { YEMA } \\
+\mathrm{CR}\end{array}$} & color & Watery & yellowish pink & whitish pink & whitish pink & yellowish pink \\
\hline & size & large & very large & large & small & pinpoint \\
\hline & form & convex & circular & wrinkled & undulate & convex \\
\hline & elevation & undulate & raised & flat & raised & raised \\
\hline & Media color & unchanged & unchanged & unchanged & unchanged & unchanged \\
\hline
\end{tabular}

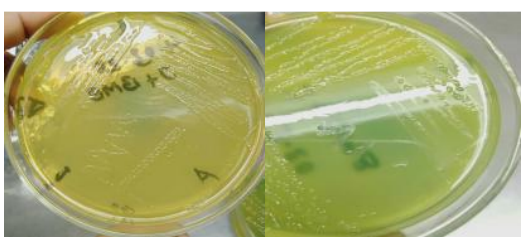

Figure 1. Colony morphology of isolate A1 from soil sample on Jensen's BMB agar media following $48 \mathrm{~h}$ of growth at $37^{\circ} \mathrm{C}$.

further cultured them in Jensen's media containing BMB and YEMA containing Congo Red to get more evidence in nitrogen fixation. All those 5 isolates took more than 7 days to get visible colonies except isolate A1 that showed good growth after $48 \mathrm{~h}$ of incubation and changed media color from green to yellow in Jensen's BMB media. The five colony morphologies were observed and their characteristics are presented
Table 2. Qualitative ammonia production capacity of isolate A1.

\begin{tabular}{cc}
\hline Day & Ammonia production \\
\hline 0 & - \\
3 & + \\
5 & + \\
7 & ++ \\
9 & ++ \\
\hline
\end{tabular}

Table 3. Microscopic observation of isolate A1.

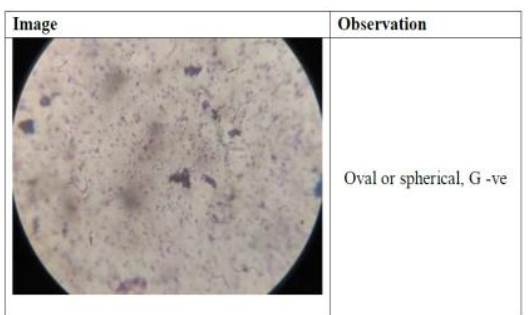


Table 4. Biochemical characteristics of isolate A1.

\begin{tabular}{ll}
\hline Tests & Results \\
\hline Oxidase & Positive \\
Catalase & Positive \\
TSI & Slant-yellow, Butt-yellow, \\
& $\mathrm{H}_{2}$ S-positive \\
MIU & Motile \\
Indole & Positive \\
Citrate & Negative \\
MR & Positive \\
VP & Negative \\
Starch hydrolysis & Positive \\
\hline Presumptively & Azotobacter sp. \\
Identified &
\end{tabular}

potential solution to all these problems due to their cost-effectiveness and eco-friendly role.

This study was focused to investigate and isolate nitrogen-fixing bacteria from soil sample which can be used as an alternative to chemical fertilizer. It is required to develop biofertilizers by determining its potent application in environment as well as cut huge costs in importing biofertilizers.

We presumptively confirmed our isolate as Azotobacter spp. based on all of our test results. Azotobacter sp. is a free $\mathrm{N}_{2}$-fixing bacterium with proven capacity of biofertilizer for soil fertility and plant growth. It has plant promoting traits as nutrient use efficiency, protection against phytopathogens, phytohormone biosynthesis, etc. as well as high resistance to environmental stress due to cyst formation which may allow its use in various environmental conditions $(9,10)$. Previous studies reported that $\mathrm{N}_{2}$-fixation in the aerobic condition is a promising criterion of the genus Azotobacter (11). Azotobacter vinelandii strain wild type isolates could excrete about $200 \mu \mathrm{M}$ (12) and 260, $251 \mu \mathrm{M}$ (13) concentrations of ammonia. Biofertilizers are carrierbased preparations containing mainly effective strains of microorganisms in sufficient numbers, which are useful for nitrogen fixation. Amongst the nutrients, nitrogen is the only nutrient, which plays a major role in the synthesis of chlorophyll, amino acids, and protein building blocks (14). Biofertilizers has substantial beneficial features in terms of their pollutant-free and in-expensive nature, in addition to its ability to utilize renewable resources along with the use of freely available solar energy, atmospheric nitrogen, and water. Moreover, they can provide vitamins and growth substances besides supplying $\mathrm{N}_{2}$ to crops (14).

\section{CONCLUSION}

As a sustainable source of nitrogen, biological nitrogen fixation for plants may replace the need for industrial nitrogen production. This study revealed that our garden soil sample contained $\mathrm{N}_{2}$-fixing bacterium which was identified as Azotobacter sp. based on morphological, physiological, and biochemical test results. This isolate can be used as a suitable candidate for the production of bio-fertilizer that helps to restore soil fertility for better crop response. Azotobacter sp. that was isolated from garden soil should be tested further in the field level to confirm their potential to be used as biofertilizer so that it can reduce the load of chemical fertilizer in crop production.

\section{ACKNOWLEDGEMENTS}

Authors are thankful to the Department of Microbiology, Stamford University Bangladesh for the technical supports provided during the study.

\section{REFERENCES}

1. Dahal B, NandaKafle G, Perkins L and Brözel VS. 2017. Diversity of free-Living nitrogen-fixing Streptomyces in soils of the badlands of South Dakota. Microbiol. Res. 195:31-39.

2. Alshibli NA. 2018. Diversity of Free - Living Nitrogen Fixing Bacteria in Soil of Sioux Prairie of South Dakota. Electronic Theses and Dissertations. 2959. https://openprairie.sdstate.edu/etd/2959.

3. Smercina DN, Evans SE, Friesen ML and Tiemann LK. 2019. To fix or not to fix: Controls on free-living nitrogen fixation in the rhizosphere. Appl. Environ. Microbiol. 85:6.

4. Shridhar BS, Author C, Shrimant Shridhar B, Shridhar BS, Author C and Shrimant Shridhar B. 2012. Review: Nitrogenfixing Microorganisms. Int. J. Microbiol. Res. 3(1):46-52.

5. Cummings S. 2005. The role and future potential of nitrogenfixing bacteria to boost productivity in organic and low-input sustainable farming systems. Environ. Biotechnol. 1(1):1-10.

6. Sadik AS, Noof AE and Sonya HM. 2016. Isolation and Characterization Of Free-Nitrogen Fixer Bacterial Strains (Azotobacter Sp.) and Their Phages From Maize Rhizosphere Soil At TAIF. Pakistan J. Biotechnol. 13(1):31-37.

7. Alves Rodrigues A, Vinicius Forzani M, de Souza Soares R, Sibov ST and Gonçalves Vieira JD. 2016. Isolation and selection of plant growth-promoting bacteria associated with sugarcane. Pesqui. Agropecu. Trop. 46(2):149-158.

8. Harley JP and Prescott LM. 2002. Laboratory Exercises in Microbiology. $5^{\text {th }}$ Edition, The McGraw-Hill Companies.

9. Aasfar A, Bargaz A, Yaakoubi K, Hilali A, Bennis I, Zeroual $\mathrm{Y}$ and Meftah Kadmiri I. 2021. Nitrogen Fixing Azotobacter Species as Potential Soil Biological Enhancers for Crop Nutrition and Yield Stability. Front. Microbiol. 12:628379.

10. Kasa P, Modugapalem H and Battini K. 2015. Isolation, screening, and molecular characterization of plant growth promoting rhizobacteria isolates of Azotobacter and Trichoderma and their beneficial activities. J Nat Sci Biol Med.6(2):360-363.

11. Brenner DJ, Noel RK and James TS. 2005. Bergeys manual Systematic Bacteriology. $2^{\text {nd }}$ edition. Springer Science Business Media, Inc. New York. USA.

12. Bali A, Blanco G, Hill S and Kennedy C. 1992. Excretion of ammonium by a nifL mutant of Azotobacter vinelandii fixing nitrogen. Appl. Environ. Microbiol. 58:1711-1718.

13. Gordon JK and Jacobson MR. 1983. Isolation and characterization of Azotobacter vinelandii mutant strains with potential as bacterial fertilizer. Can. J. Microbiol. 29:973-978.

14. Alhia BMH. 2010. The Effect of Azotobacter chrococcum as Nitrogen biofertilizer on the growth and yield of Cucumis $\begin{array}{lll}\text { Sativus. } & \text { December } & \end{array}$ http://hdl.handle.net/20.500.12358/21551. 